\title{
Performance of a Single Well Surfactant Tracer Test in the Gullfaks Field, Norway
}

\author{
Nordbotten A., Maldal T., Gilje E., Svinddal St., Kristensen R.
}

\author{
Statoil a. s., Norway
}

\begin{abstract}
Copyright 1986, Steering Committee of the European IOR - Symposium.
This paper was presented at the Oth. European IOR - Symposium in Vienna, Austria, May 15 - 17, 1996

This paper wes selected for presentetion by the Steesing Committee, following review of information contained in an abstrect

submitted by the author(s). The paper, as presented hes not been roviowed by the Steering committee.
\end{abstract}

\begin{abstract}
The surfactant test initiated in a Gullfaks Well in January $1991^{\ddagger}$, was interrupted before surfactant injection due to operational problems in the well. Based on this experience, a new well was identified, and a single well surfactant injection test was planned and conducted during the first half year of 1992. The results, and a discussion of both the results and the experiences, are presented for the two well operations.
\end{abstract}

The main objective of the test was to evaluate the efficiency of the surfactant to mobilize oil at reservoir conditions, by measuring the residual oil saturation after water tooding, and after the surfactant was injected.

The residual oil saturation was measured by the SWCT method, applying ethyl formate as the reactive tracer. A cotal of six SWCT tests were performed during the operations. In both wells, extensive data collection programs were executed. This included measurements of fluid saturations (GST logs), fluid inflow and outflow pertormances (PLT logs,) as well as $\mathrm{pH}$, ionic composition, and gas content in the back produced fluid. These data were integrated in the evaluation of the SWCT tests, and proved to be crucial in understanding and interpreting reservoir processes during testing. A chemical flood simulator was used to model the tracer profiles from the SWCT tests.

Special attention was paid to the reduction of $\mathrm{pH}$ in back produced water due to hydrolysis of ethyl formate, and the reduced gas content in back produced water due to stripping of light components of the residual oil by the injected water.

The residual oil saturations interpreted from these tests, showed that between 40 and $70 \%$ of the remaining oil after water flooding was mobilized by the surfactant.

\section{Introduction}

In cooperation with Berol Nobel, Sweden, a surfactant system showing high efficiency in laboratory core flood experiments was developed. The surfactant system which is a branched ethoxylated sulphonate, was in june 1990 decided to be tested in a single well, and 9 tons of active surfactant were produced.

A $16 \mathrm{~m}$ thick, isolated, highly permeable, and oil saturated zone in a producing well, was chosen for the test.

The test procedure was to waterflood the zone, measure $S_{\text {or }}$ inject the surfactant, and then measure $S_{\text {or }}$ again.

Details about the surfactant system, well configuration, reservoir properties. and planned test procedure was presented by E. Gilje et. al. ${ }^{\text {I }}$

To measure residual oil saturation the ester-based single well tracer test method (SWCT), developed by Deans ${ }^{3}$, was chosen. This method is briefly described below:

1. A slug of water containing a partially oil soluble primary tracer (ester) is injected

2. The tracer slug is pushed to a predetermined distance from the well by injecting more water

3. The well is shut in to allow the primary tracer to hydrolyse and form a secondary tracer (alcohol) which is only soluble in water.

4. When sufficient amounts of the secondary tracer is 
formed, the well is back produced, and the tracer concentrations in the back produced water are measured.

Due to different partitioning between oil and water, the two tracers will approach the well with different velocities, and this difference will be a measure of the residual oil.

The main advantage with this method compared to conventional logging techniques is that it measures $S_{\text {or }}$ deeper into the reservoir. The $S_{\text {or }}$ obtained from a SWCT test will be a volumetric average.

A similar test was performed in the Oseberg Field ${ }^{2}$ in 1992 by Norsk Hydro under isothermal conditions, and with another surfactant system. The isothermal conditions were obtained by heating the injection water to $80^{\circ} \mathrm{C}$. In Gullfaks, the test was performed with normal injection water, holding $25^{\circ} \mathrm{C}$ at wellhead. When injecting this water the test zone is cooled down from the initial reservoir temperature of $70^{\circ} \mathrm{C}$.

Both for detailed planning of each SWCT test, and to interpret the test results afterwards, extensive simulation studies were done both by Statoil and the consulting company that conducted the tests offshore.

The simulation results presented in this paper are derived from the Statoil simulations performed with the chemical flood simulator Scorpio, developed by AEA Technology.

\section{Test performance in well no. 1}

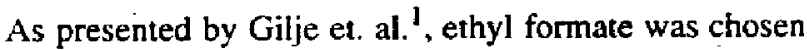
as the primary tracer in the SWCT tests with isopropanol and methanol as material balance tracers. Ethyl formate was chosen because injection of cold sea water at a rate of $1500 \mathrm{~m}^{3} /$ day was expected to cool the test zone from 70 to $30{ }^{\circ} \mathrm{C}$, which is favourable for applying ethyl formate as the primary tracer in the SWCT test.

Due to the dipping reservoir, the water injection period prior to the test was designed as long as 21 days to counterbalance gravity, and thereby keep mobile oil away from the test zone until the second SWCT test was completed.

When injecting the tracer slugs, the injection rate was reduced to $318 \mathrm{~m}^{3} /$ day due to limitations in the chemical pump, and to better control the tracer injection. The push water was still injected at $1500 \mathrm{~m}^{3} /$ day.

To examine possible saturation gradients in the test zone, the SWCT test was designed with two slugs in the same test ${ }^{1}$. Based on simulations, the spacing between the two slugs was expected to be large enough to produce them back as two separate slugs.

As shown in Fig. 6, this did not happen. The first slug arrived earlier than expected, and the second slug was far more dispersed than expected.

The probable reason for the early back production of tracers was a leakage of injected fluid to an underlying reservoir zone through a bridge plug separating the test zone from the perforations underneath. Due to lower reservoir pressure in the underlying zone, it behaved as a thief zone, and did not contribute to the back production.

The leakage was confirmed by a PLT log after the tracers were back produced, while a PLT in the water injection period did not show any leakage.

It has not been possible to determine the exact start of the leakage, but it has probably arised early in the tracer injection period and increased gradually towards end of injection. The larger loss of the injected methanol (25\%) than ethyl formate (20\%), support this theory since methanol was injected both together with the ethyl formate, and in the push water behind.

The loss of injected fluid in the different phases of the SWCT test was estimated to $0-13 \%$ of the first tracer slug, $0-15 \%$ of the first push volume, about $20 \%$ of the second tracer slug, and about $45 \%$ of the second push volume.

Because of the nonideal tracer responses and the leaking bridge plug it was decided to stop the test; and start planning for a second trial.

\section{Test design in well no. 2}

The new test was planned in a similar sand as in well no. 1 but the thickness of the test zone was only $7 \mathrm{~m}$. The reservoir dip angle is $12^{\circ}$, and the well deviation angle through the test zone is $44^{\circ}$ from vertical. A sketch of the well configuration projected in the reservoir dip direction, is shown in Fig. 1 below.

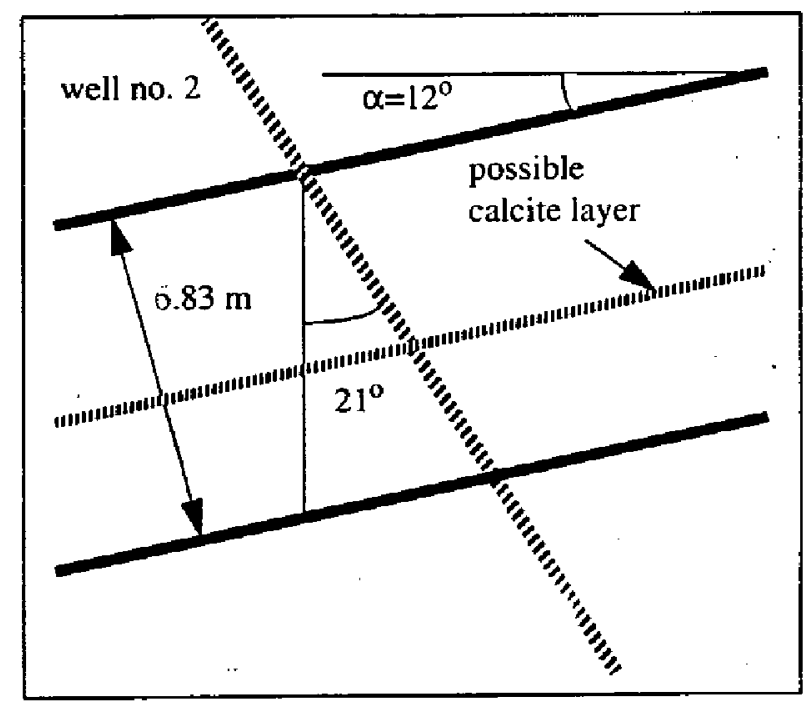

Fig. 1. Well configuration well no. 2 


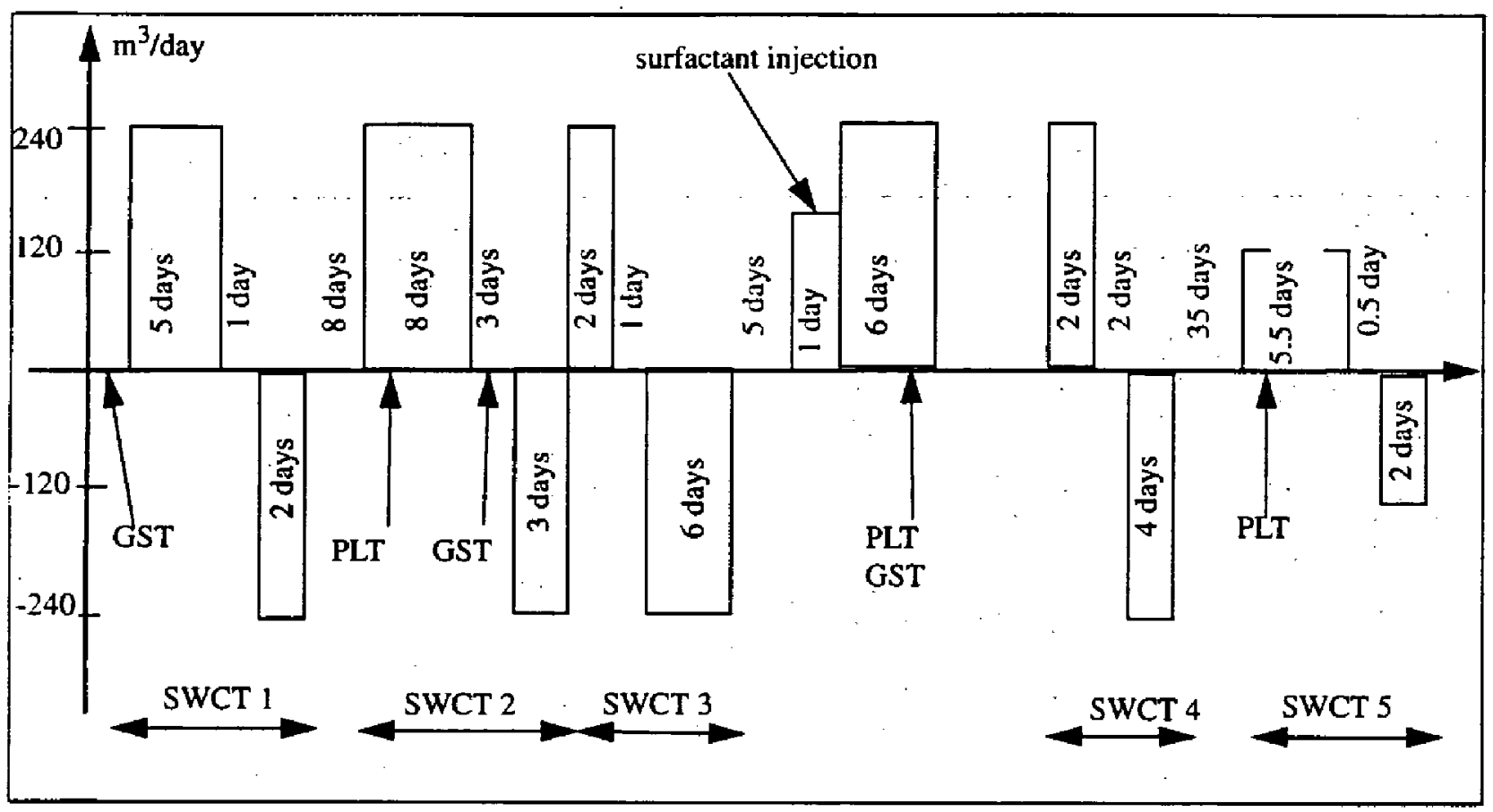

Fig. 2. Test schedule in well no. 2

The basic reservoir properties as implemented into the simulation model is listed in Table 1 below.

\begin{tabular}{|l|l|l|l|l|}
\hline Layer & $\Delta \mathrm{z}(\mathrm{m})$ & \multicolumn{1}{|c|}{$\Phi$} & $\mathrm{K}_{\mathrm{h}}(\mathrm{mD})$ & $\mathrm{K}_{\mathrm{v}}(\mathrm{mD})$ \\
\hline \hline $\mathrm{I}$ & $\mathrm{I} .07$ & 0.372 & 8038 & 6542 \\
\hline 2 & 2.41 & 0.362 & 6223 & 4630 \\
\hline 3 & 1.10 & 0.367 & 12718 & 11285 \\
\hline 4 & 1.10 & 0.332 & 12718 & 11285 \\
\hline 5 & 1.15 & 0.336 & 2279 & 1440 \\
\hline
\end{tabular}

Table 1. Reservoir properties of well no. 2

The test zone was initially oil saturated, but a GST run before the test showed that the lower part of the zone was waterflooded (layer $3-5$ in Table 1). Since more than half of the test zone still was oil saturated, this did not affect the need of water flooding to prevent mobile oil from migrating back into the test zone during the SWCT tests.

The injection rate is more critical in Gullfaks than it was in the Tarbert formation at Oseberg ${ }^{2}$ due to a more favourable CDC curve ${ }^{5}$. One of the experiences from well no. 1 was that a lower injection rate was desirable to avoid flushing of residual oil due to high fluid velocity near the well bore, and that the rate should be kept constant through all test phases.

Based on simulations a rate of $240 \mathrm{Sm}^{3} /$ day was found to be suitable both for injection and production, assuming that the inflow and outflow was equally distributed over the test interval.
Based on experience from well no. 1, the SWCT test design was kept as simple as possible with only one tracer slug in each SWCT, but that it should be possible to measure $S_{\text {or }}$ within a distance of $10 \mathrm{~m}$ from the well bore.

Coreffood experiments at reservoir conditions performed after the test in well no. 1, showed that the selected surfactant did not mobilize any oil unless the oil contains some dissolved gas. A similar test design as in well no. 1 , with large volume of water injected prior to the test would strip the light components from the remaining oil in the test zone.

The challenge was to inject enough water to prevent mobile oil from influencing the SWCT tests, and still retain enough light components in the residual oil for the surfactant to mobilize oil from the test zone.

Short water injection periods prior to each SWCT instead of one long water injection period as in well no. 1 , was introduced. The advantage of this approach is injection of smaller volume of water at lower rate. The disadvantage is less cooling of the reservoir which might imply less favourable and more uncertain conditions for the hydrolysis of ethyl formate in the SWCT tests.

To reduce some of these uncertainties a SWCT test with smaller volumes (mini test) was designed to examine parameters like temperature, rate of hydrolysis, fuid drift and dispersion. If successful this test would also give a valuable measure of $S_{\text {orw }}$ within a radius of $4 \mathrm{~m}$ from the well bore.

A sketch of the complete test design as it was conducted is illustrated in Fig. 2, and the detailed design of each SWCT test without preinjection of water is summarized in Table 2 


\begin{tabular}{|l|l|l|l|l|}
\hline $\begin{array}{c}\text { Test } \\
\text { no. }\end{array}$ & $\begin{array}{c}\text { chemical } \\
\text { mix } \\
\text { (days) }\end{array}$ & $\begin{array}{c}\text { push } \\
\text { water } \\
\text { (days) }\end{array}$ & $\begin{array}{c}\text { shut in } \\
\text { (days) }\end{array}$ & $\begin{array}{c}\text { back } \\
\text { production } \\
\text { (days) }\end{array}$ \\
\hline \hline 1 & 0.17 & 0.51 & 1.16 & 3.04 \\
\hline 2 & 0.20 & 1.19 & 3.675 & 3.24 \\
\hline 3 & 0.16 & 0.50 & 1.09 & 1.26 \\
\hline 4 & 0.20 & 1.17 & 2.03 & 2.56 \\
\hline 5 & 0.33 & 1.00 & 0.51 & 1.96 \\
\hline \hline
\end{tabular}

In test no. 1 no material balance tracers were applied. Test 5 was performed with lower rates $\left(120 \mathrm{~m}^{3} /\right.$ day)

Table 2. Test design SWCT tests in well no. 2

The volumes of push water in Table 2 include the well bore volume of $45 \mathrm{~m}^{3}$, which was excluded from the simulations.

The injected tracer concentrations was 1.5 vol.\% ethyl formate, $0.5 \%$ isopropanol and $0.5 \%$ methanol in the chemical mix, and $0.5 \%$ methanol in the push volume. The ethyl formate concentration was increased from $1.0 \%$ in well no. 1 to make the SWCT tests less sensitive to rate of hydrolysis.

\section{Data collection program}

In both wells an extensive data collection program was executed. In addition to fluid rates and chemical concentrations the following data were collected in both wells.

- Bottomhole temperature and pressure during the whole test sequence except SWCT test no. 5 in well no. 2 .

- PLT logs when injecring water, two in well no. 1 and three in well no. 2 as indicated on Fig. 2 .

In well no. 2 the program was supplemented with the following measurements:

- 'Gas content in back produced water.

- Gas and water samples for analysis of composition. Water samples were collected from all the SWCT tests, while gas samples were only collected in SWCT test no. 1 .

- $\mathrm{pH}$ in backproduced water, except in SWCT test no. 1.

- 3 GST logs as indicated on Fig. 2

\section{Test performance well no. 2}

This test was initially planned without SWCT no. 3 and 5 , which were added due to the nonideal behaviour of both test no. 1 and 2, as shown in Fig. 7 and Fig. 9.

Since a major difficulty in SWCT test no. 2 was the small amounts of ethyl formate backproduced, it was expected that further tests with smaller test volume and shorter shut in time would be easier to interpret.

As illustrated in Fig. 4, these expectations were attained, but a large reduction in $\mathrm{pH}$ due to ester hydrolysis, was observed, which complicate the interpretation as discussed by several authors ${ }^{2,4}$. The SWCT test no. 3 gives, in spite of these problems,an excellent basis for obtaining a reasonable estimate of $S_{\text {orw }}$

The injection of surfactant was successfully performed after SWCT test no. 3. $200 \mathrm{~m}^{3}$ of water with $2 \%$ surfactant was injected at an average rate of $145 \mathrm{~m}^{3} /$ day. The injection rate was reduced from the planned $240 \mathrm{~m}^{3} /$ day because of limited capacity on the chemical pump that brought the surfactant into the well stream.

SWCT test no. 4 behaved as expected until 15 hours of the backproduction. At that time a sudden drop in the tracer concentration occurred as shown in Fig. 11. Shortly after test no. 4, the well had to be shut in due to sand production, which is considered as the reason for the drop in tracer concentrations.

Sand was cleaned out of the well before SWCT test no. 5 was conducted. No interpretable results were obtained from that test, probably because some polymer was lost into the formation during sand cleaning operations.

An important deviation from the expected performance was the fact that the injected water only went into the lower part of the test interval, below the calcite layer indicated in Fig. 1.(layer 3 and 4 in Table 1). This probably reduces the height of the real test interval and thereby increase the fluid velocities from what was assumed in the test design.

\section{Test interpretation}

The main objective of the test interpretation was to determine $S_{\text {or }}$ prior to, and after surfactant flooding. This was done by simulating the SWCT tests with the chemical flood simulator, Scorpio, to match the backproduced tracer concentrations.

To avoid too complicated simulation runs, each SWCT test was simulated individually staring with an appropriate water injection period to match the cumuiativ amount of injected water in the formation at the beginning of each SWCT test. When matching each SWCT test, care was taken to do model modifications that retained consistency between the tests.

$S_{\text {orw }}$ was basically determined from the ideal behaving 
SWCT test no. 3, while $S_{\text {orc }}$ had to be determined from the more complicated SWCT no. 4 since SWCT no. 5 did not give any interpretable information. SWCT test no. 1 and 2 were simulated with the aim of obtaining a reasonable match with the same $S_{\text {or }}$ as in SWCT test no. 3.

Important matching parameters were dispersion, rate of hydrolysis, $S_{o r}$ and well inflow performance. The latter was modified to match nonideal behaviour based on results from the data collection program described in Section 4.

In the matching procedure well properties and dispersion were adjusted first to match the behaviour of the material balance tracers. Afterwards $S_{o r}$ and rate of hydrolysis were adjusted to match the behaviour of ethyl formate and ethanol.

\subsection{Partitioning data}

To obtain a reliable value of $S_{\mathrm{or}}$ from the simulations, laboratory measured partitioning coefficients of ethyl formate between seawater and Gullfaks oil proved to be crucial. From the first measurements made prior to the test in well no. 1, set no. 1 in Fig. 3 was selected as input to the simulations. This set was obtained at $30^{\circ} \mathrm{C}$, which was close to the reservoir conditions during the test in well no. 1 .

In well no. 2 the reservoir temperature during the SWCT tests appeared to be between 35 and $45^{\circ} \mathrm{C}$. Some inconsistency was discovered in the previous measured data for this temperature range, leading to new measurements performed at 30,40 and $50{ }^{\circ} \mathrm{C}$. From these measurements, that appeared to be less sensitive to temperature, set no. 2 in Fig. 3 was selected as input to the simulator.

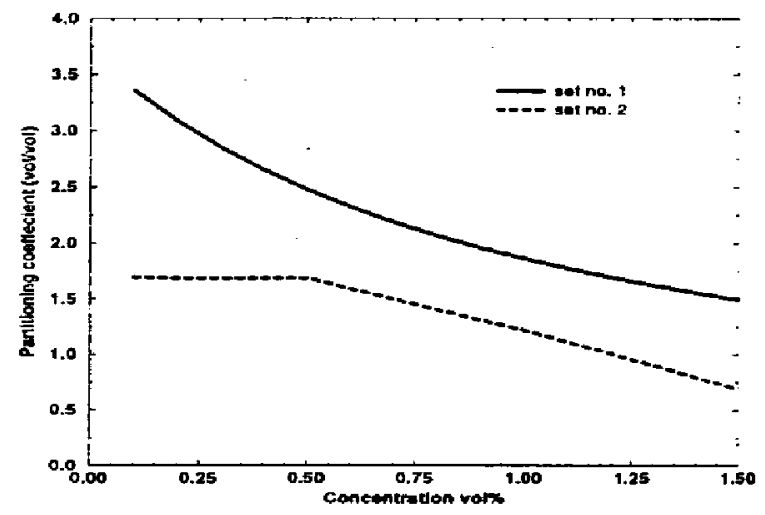

Fig. 3. Partitioning coefficient of ethyl formate between oil and water

A thorough review of the laboratory measurements pointed out that the first set might have been affected by hydrolysis of ethyl formate such that set no. 2 should be considered as the most reliable. Simulations with both sets showed that $S_{\text {or }}$ after waterflooding differs by 6 to 7 saturation units. For lower oil saturations the difference will be smaller. Sensitivity simulations on SWCT test no. 3 also indicated that a constant value of the partitioning coefficient for ethyl formate concentration lower than $0.5 \%$ makes it easier to achieve a reasonable match than the increasing trend in set no 1 .

\subsection{Rate of hydrolysis}

As shown in Fig. 4, a significant reduction in $\mathrm{pH}$ was observed in the backproduced water from SWCT test no. 3 , indicating that the rate of hydrolysis has varied during the SWCT test. Similar variations in $\mathrm{pH}$ were also observed in the other tests where $\mathrm{pH}$ was measured

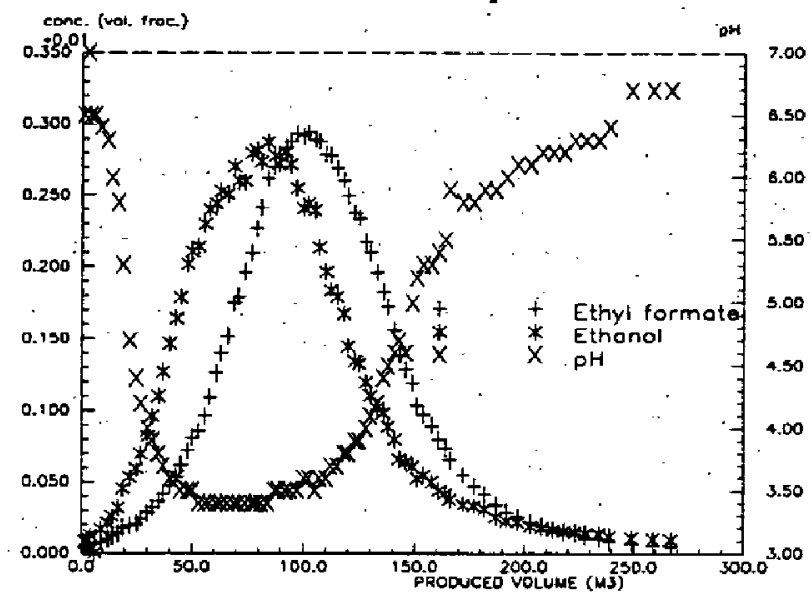

Fig. 4. Tracer profiles and pH in SWCT test no. 3

Laboratory measurements of hydrolysis at $35{ }^{\circ} \mathrm{C}$ show that the rate of hydrolysis increases with decreasing $\mathrm{pH}$ (Fig. 5). Since pH drops rapidly below 5.0 when adding $1.5 \%$ ethyl formate into seawater, it is not likely to expect these tests to be affected by reduced rate of hydrolysis during the shut in period as discussed by Wellington et. al. ${ }^{4}$.

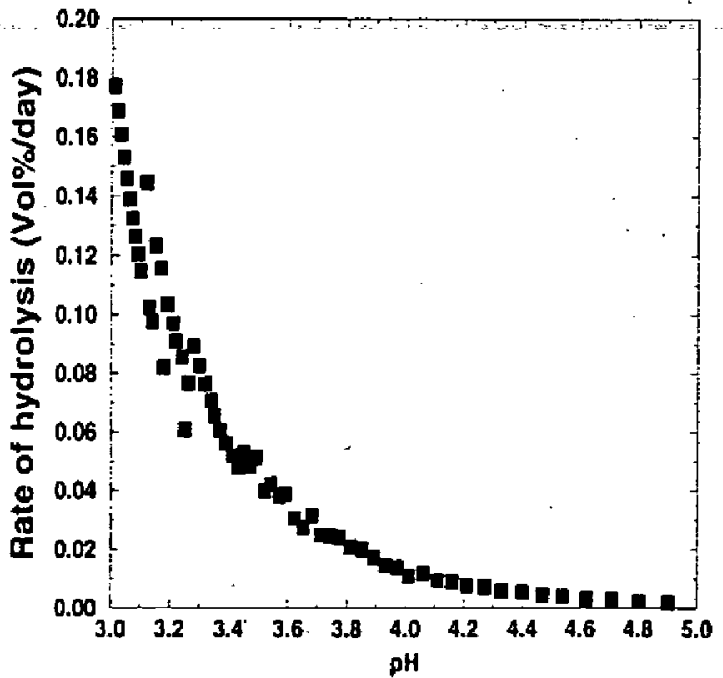

Fig. 5. Measured rate of hydrolysis for ethyl formate

However, the rate of hydrolysis has not been constant through the testing, but has probably been increasing, from a rather low rate during injection phase to a 
maximum rate in the backproduction phase. An increase of bottomhole temperature from injection to back production will also contribute to increase the rate of hydrolysis

In the simulations, hydrolysis was modelled as a function of ethanol concentration, reflecting that increased concentration of ethanol will coincide with a reduction of $\mathrm{pH}$. The dependency was based on the laboratory measurements shown in Fig. 5, and adjusted to match the observed amounts of hydrolysis in each SWCT test.

\subsection{SWCT test in well no. 1}
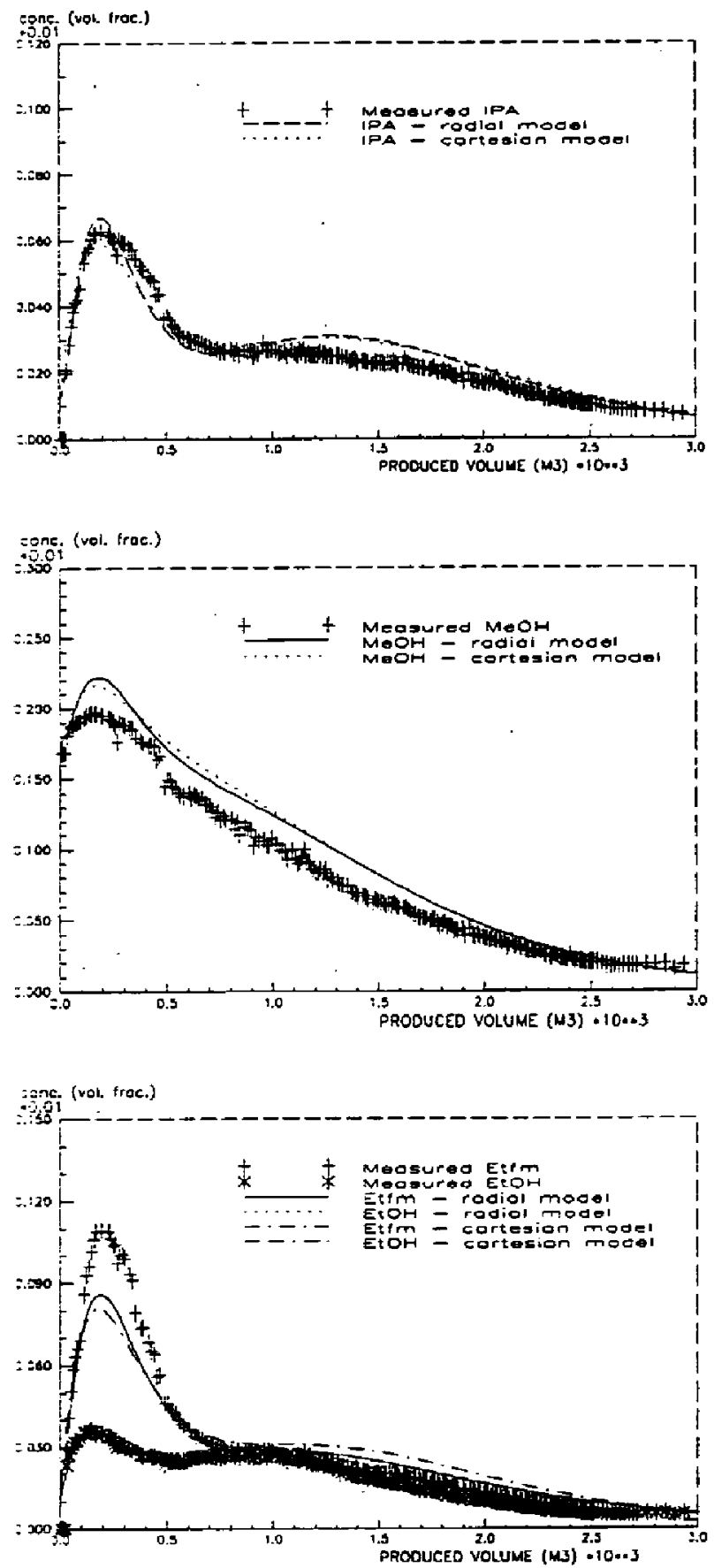

Fig. 6. Measured and simulated tracer profiles from well no. 1

The test in well no. 1 was primarily modelled by a 3D model to be able to include both the reservoir dip and the well deviation angle.

The SWCT test in well no. 1 was first evaluated in 1991, with the partitioning coefficients set no. 1 in Fig. 3, and the re-evaluated with the partitioning data set no. 2 after evaluation of the SWCT tests in well no. 2. The latter evaluation concluded with $S_{\text {orw }}=0.22 \pm 0.06$, an increase of 6 saturation units from the first evaluation.

After a match was achieved by the 3D model some sensitivities with a 2D radial model were run. As shown in Fig. 6, these sensitivities compared well with the 3D results. The only modifications was to increase the dispersion coefficients in the radial model, which basically accounts for the finer grid in this model.

Since the radial model requires much less computer time, and is easier to handle a consequence of this experience was to apply a $2 \mathrm{D}$ radial model to evaluate the test in well no. 2 .

\subsection{SWCT test no. 1 in well no. 2.}

SWCT test no. 1 is characterized by an unexpected early peak on the tracer profiles as shown in Fig. 7.

A possible explanation for the early peak is that the flow interval, confirmed by the PLT log prior to SWCT test no. 2 was not completely opened before the back production started. As a consequence a part of the interval would receive injected fluid at a low rate, but produce back at a higher rate leading to an early arrival of tracers.

An observed 2.5 bar drop in bottomhole pressure when shutting in the well compared to only one bar when opening the well may support this theory since this difference in pressure drop was not observed in the remaining test sequence.

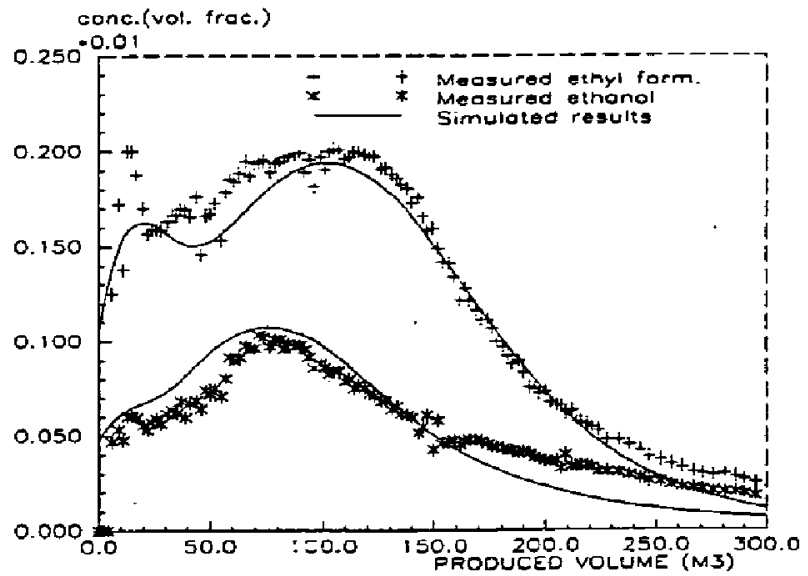

Fig. 7. Tracer profiles in SWCT test no. 1 in well no. 2

The rapid increasing GWR in SWCT test no.l (Fig. 8) also indicates nonreversible flow. Based on the cumulative amounts of injected water in the test zone, GWR was expected to increase exponential as in SWCT no. 3 (Fig. 8). 
The assumptions discussed above were implemented in the simulation model, and an acceptable match was achieved with the same residual oil saturation as for the ideal behaving SWCT test no. 3 (see Fig. 7).

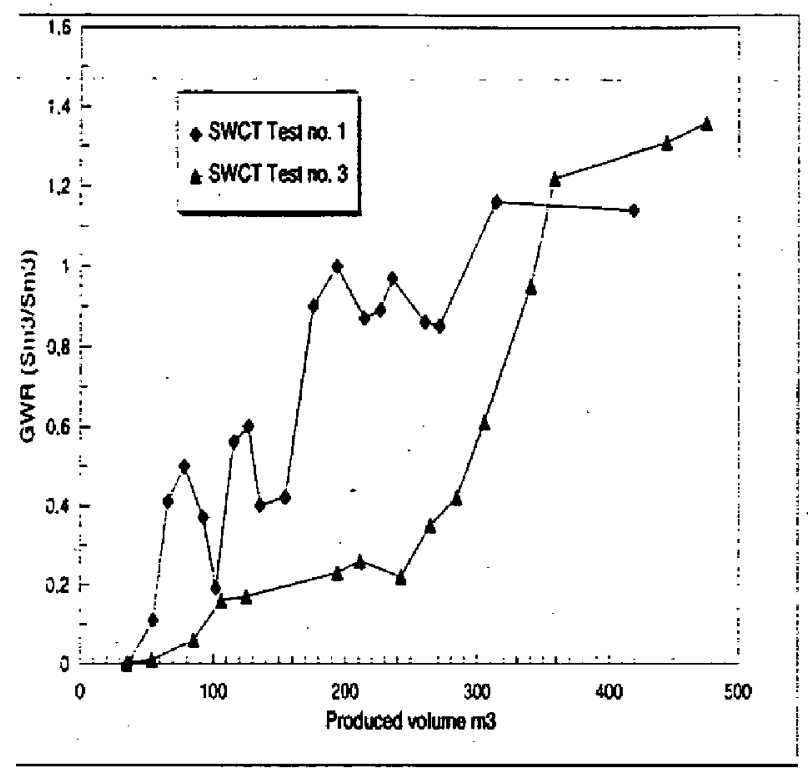

Fig. 8. Observed GWR in SWCT test no. 1 and 3

\subsection{SWCT test no. 2 in well no. 2}

In SWCT test no. 2 the rate of hydrolysis was higher than expected probably due to higher reservoir temperature than in SWCT test no I. The tracers were backproduced at a bottomhole temperature between 42 and $45^{\circ} \mathrm{C}$ compared to 38 to $40^{\circ} \mathrm{C}$ in SWCT test no. 1 .

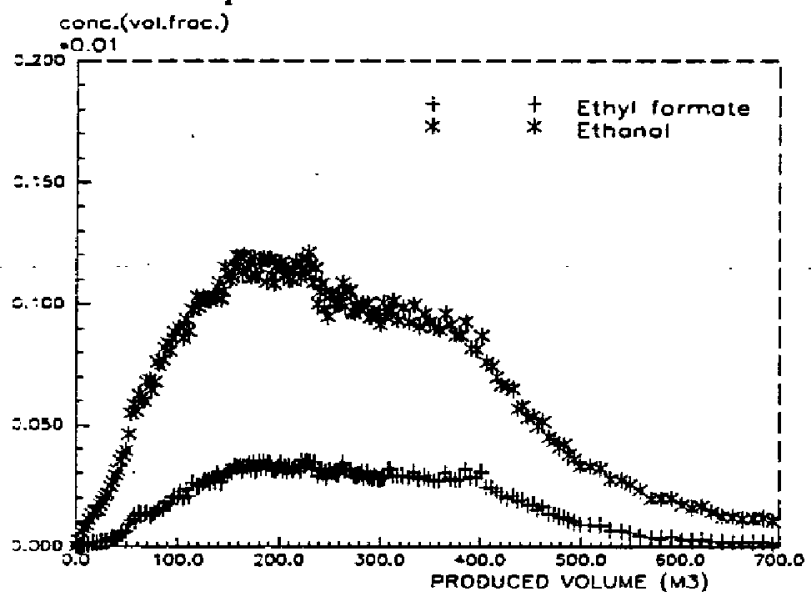

Fig. 9. Produced tracer profiles in SWCT test no. 2

The tracer profiles shown in Fig. 9 are characterized by their extended shape and low concentrations of ethyl formate, making it hard to identify the peak concentrations and obtain a reliable estimate of $S_{o r}$

The simulations matched the front part of the tracer profiles, but did not match the extended shape of the tracer profiles. Different from SWCT test no. $l$, the other collected data did not give any explanations for the nonideal behaviour.

However, a possible explanation might be fluid drift from a producing well $800 \mathrm{~m}$ away from the test well. Because the shut in period in this test is three times longer than for SWCT test no. 1 and 3 and the tracer are pushed further away from the well, fluid drift may have influenced this test without influencing the other two.

Due to the low concentrations of ethyl formate and the success of SWCT test no. 3, no attempt was made building a model for this test that could evaluate the fluid drift opportunity.

\subsection{SWCT test no. 3 in well no. 2}

SWCT test no: 3 performed ideally as shown in Fig. 10, and was modelled with reversible flow from layer 3 and 4 in the model (see Table 1), giving a good match of the material balance tracers as shown in the upper part of Fig. 10.

The lower part of Fig. 10 shows normalized concentrations of backproduced ethyl formate and ethanol simulated with two different values of $S_{\text {or }}$ From these simulations $S_{o r}=0.21 \pm 0.04$ was concluded as the best estimate of $S_{\text {or }}$ prior to surfactant flooding.
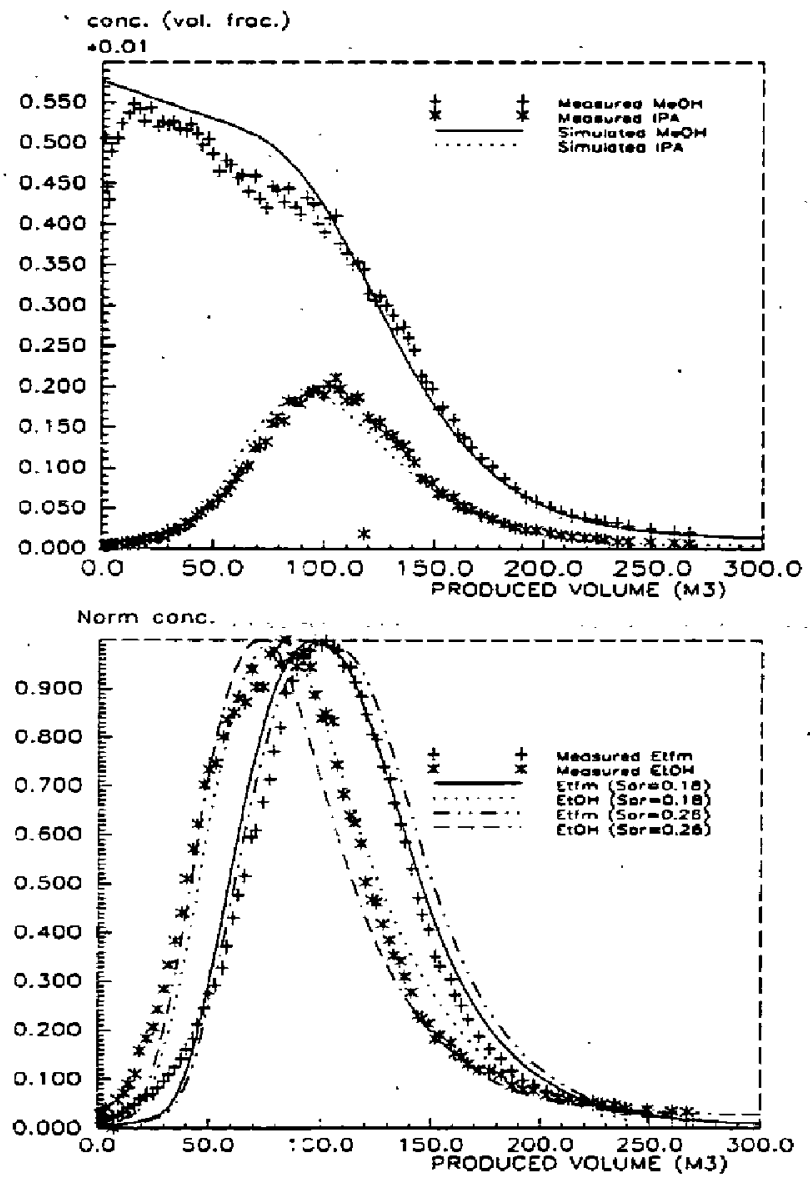

Fig. 10. Final match of SWCT test no. 3

\subsection{Well no. 2 after surfactant flooding}

Due to the sand problems in SWCT test no. 4, and the lack of success in SWCT test no. j, only the front part of SWCT no. 4 was applicable for determining $S_{\text {or }}$ after surfactant flooding, a fact that increases considerably the uncertainty. 

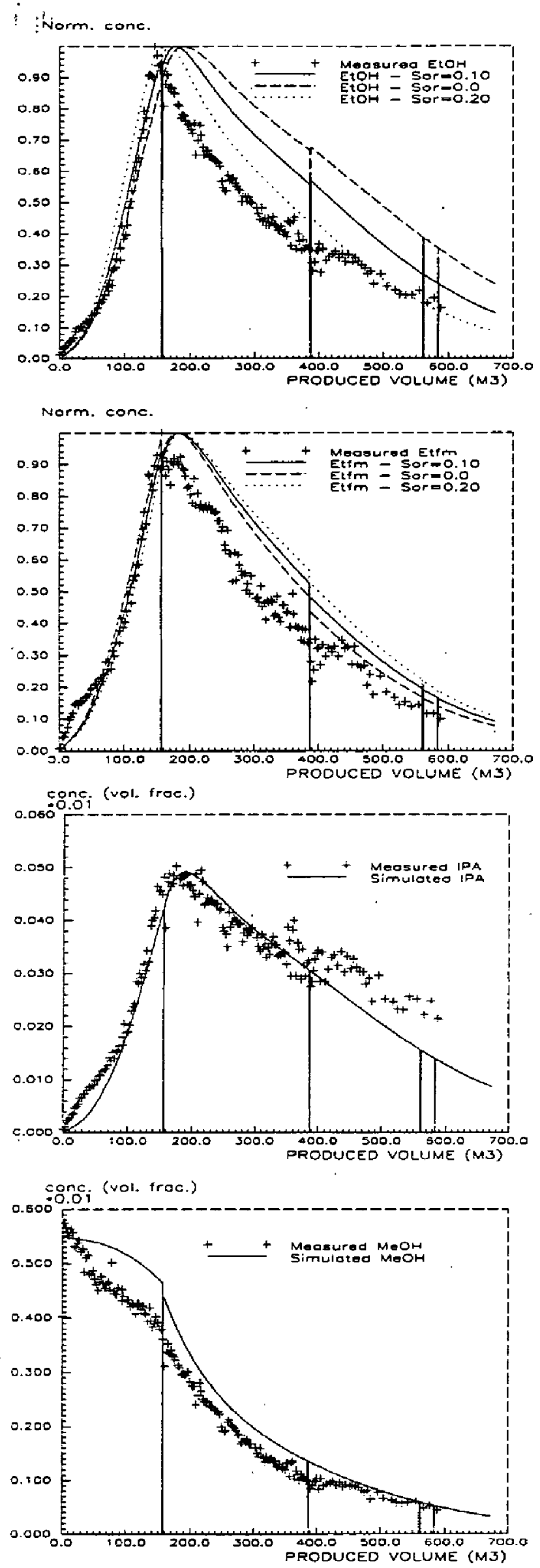

Fig. 11. Simulated performance of SWCT no. 4
The sudden drop in tracer concentrations after 20 hours of back production has been explained as inflow of water from above the calcite layer indicated on Fig. 1, caused by formation sand restricting the flow from the lower interval.

Both a drop in bottomhole pressure, indicating reduced productivity, and an increased temperature gradient, indicating inflow of warmer fluid, support this theory. The same is the case with the GWR measurements which are equal to SWCT test no. 2 until a sudden increase which coincides with the drop in tracer concentrations.

Simulations showed that $S_{\text {or }}$ less than 0.15 matches the tracer concentrations from the first 20 hours of back production properly, while $\mathrm{S}_{\mathrm{or}}=0.20$ gives 100 early arrival of ethanol. These results are illustrated in Fig. 11.

Another approach to obtain a better estimate of $S_{\text {or }}$ was to compare the first $200 \mathrm{~m}^{3}$ of the normalized back production of ethanol from SWCT no. 2 and 4, to obtain an estimate of the change in $S_{\text {or }}$ Since the injected volumes in these test are equal, the ethyl formate curves are expected to overlay, and the difference in the ethanol curves should then reflect the change in $S_{\text {or }}$

As seen from Fig. 12 and Fig. 13 the difference between the ethanol curves is larger than between the ethyl formate curves, showing that the surfactant has mobilized some oil.

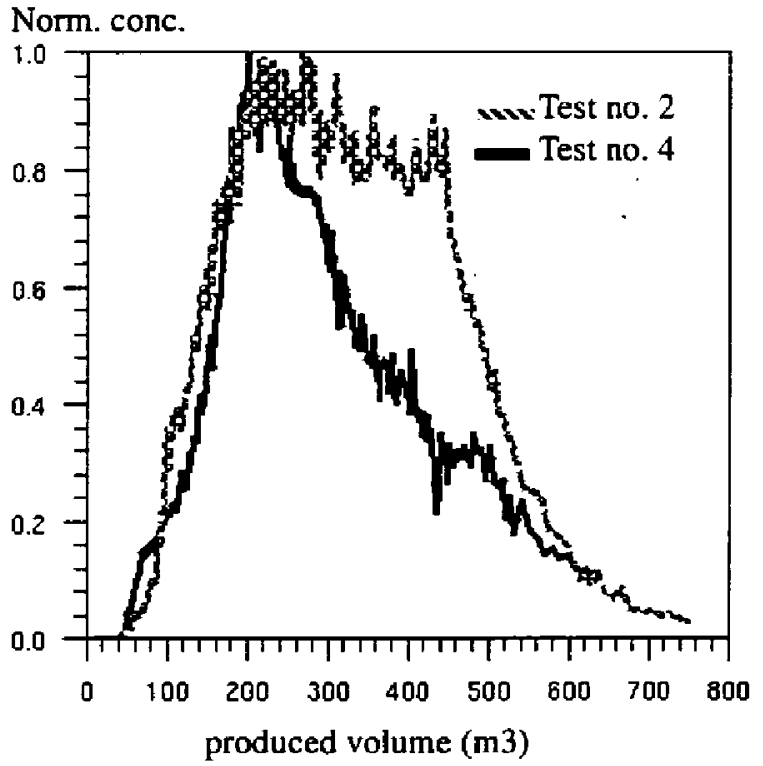

Fig. 12. Normalised back production of ethyl formate in SWCT Test no. 2 and 4.

To quantify the change in oil saturation, an average distance between the ethanol curves in Fig. 13 was calculated. Assuming a constant partitioning coefficient of 1.7 , and neglecting hydrolysis during back production, the reduction in oil saturation was estimated to $0.10-0.12$.

With $S_{\text {or }}$ after water flooding as determined from SWCT 
test no.3, oil saturation after surfactant flooding was estimated to $0.10 \pm 0.05$.

Norm. conc.

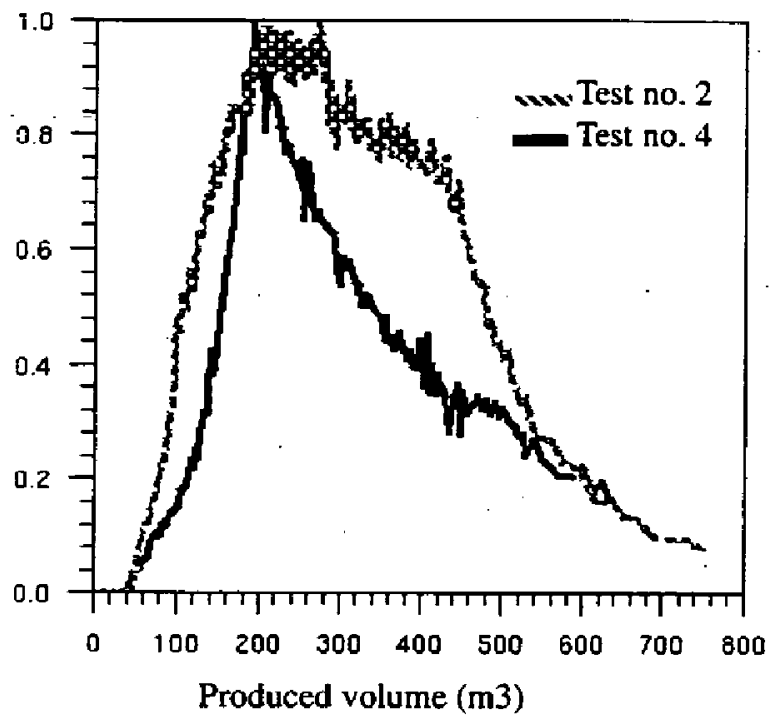

Fig. 13. Normalized back production of ethanol in SWCT Test no. 2 and 4.

\section{Discussion}

When trying to generalise the results from a single well test to an interwell situation there are several factors to be aware of.

One of the most important is stripping of gas from the residual oil by the injected water, which will particularly affect the near weil area.

A second factor is that high fluid velocity close to the well bore will increase the capillary number enough to Hush some of the residual oil that would have been left as residual oil elsewhere in the reservoir.

Both factors above may lead to a low estimate of $S_{o r}$ that can be corrected for. Corrected for gas stripping, the results from well no. 2 would have been $S_{\text {orw }}=0.25 \pm 0.05$, and $S_{\text {orc }}=0.13 \pm 0.06$, while $S_{\text {orw }}$ in well no. 1 would have been $0.27 \pm 0.07$.

Coreflood experiments under reservoir conditions showed that the surfactant did not mobilize any oil unless the oil contained some dissolved gas. With the selected design the surfactant might not have mobilized any oil within a distance of three meter from the well, but since $S_{\text {or }}$ was measured within a distance of $9-10 \mathrm{~m}$ the influence on the average $S_{\text {or }}$ is less than one saturation unit.

This effect was estimated to 3 saturation units for $S_{\text {orw }}$ in well no. 2 and 1 saturation unit in well no. 1 . For $S_{\text {orc }}$ this correction is considered to be less applicable, and has not been calculated.

Since the reservoir volume examined by the SWCT tests not necessarily coincide with the volume actually flooded by the surfactant, the results can not be used for optimizing the amounts of surfactant in a field implementation.

During back production the measured surfactant concentration in back produced water did not exceed 120 ppm, compared to the injected concentration of 20,000 ppm. Due to the sand problems back production had to be stopped too early to obtain any conclusive information about surfactant retention from the test.

However, the observed $S_{\text {orw }}$ both in well no. $I$ and 2 . is lower than previously expected ', making surfactant flooding less attractive.

An important observation was that the reported uncertainty of 2 - 3 saturation units ${ }^{6}$ was not achievable in any of the SWCT tests on Gullfaks, because the separation between the ethanol slug and the ethyl formate slug was not sensitive enough to $S_{o r}$ This is illustrated in Fig. 10 for the ideal behaving SWCT test no. 3 .

The main reason for this is the low partitioning coefficient of ethyl formate, compared to ethyl acetate which is most commonly used in SWCT tests ${ }^{7}$. Reported partitioning coefficients for ethyl acetate are in the range of 4 - 8 compared to about 2.0 , or lower for ethyl formate ${ }^{7}$.

Further, the injection time is long compared to the shut in period, which will reduce sensitivity to $S_{\text {or }}{ }^{7}$. To evaluate how this affected SWCT test no.3 it was simulated both with increased and reduced shut in time. As shown in Fig. 14 increased shut in time would have given earlier back production of ethanol, but not enough to reduce uncertainty

Norm conc.

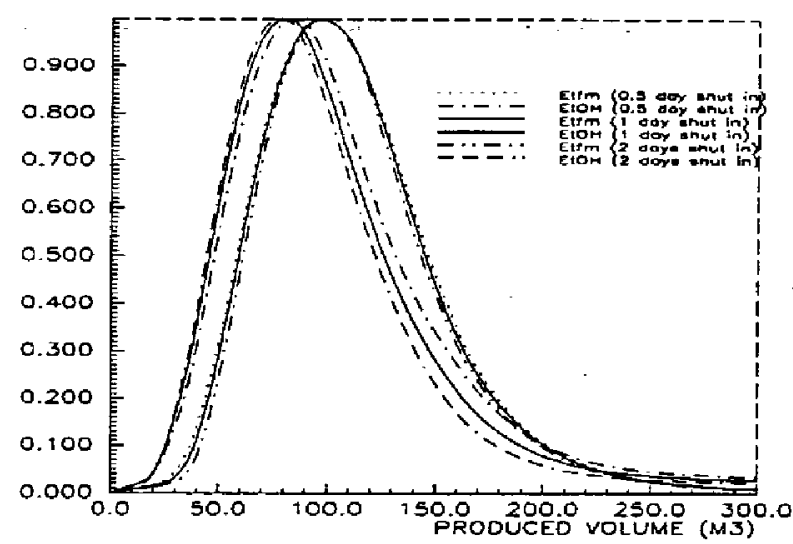

Fig. 14. Simulated SWCT no. 3 with various shut in periods.

\section{Conclusions}

- The surfactant was successfully injected without any special treatment of the injection water

- Between 40 and $70 \%$ of the remaining oil after water flooding was mobilized by the surfactant, as the $S_{\text {or }}$ 
was interpreted to $0.21 \pm 0.04$ after waterflooding and $0.10 \pm 0.05$ after surfactant flooding.

- The extensive data collection program proved to be crucial for interpreting and understanding the test results

- Due to lower $S_{\text {orw }}$ than expected in both wells, the test has made surfactant flooding less attractive in the Gullfaks field.

- Both pH and reservoir temperature proved to be important parameters to consider when planning and interpreting a SWCT test.

- Ethyl formate as primary tracer lowers the expected accuracy of the SWCT method due to small partitioning coefficient.

- To apply more than one tracer slug in a SWCT test as in well no. 1 should not be recommended.

\section{Nomenclature}

$\begin{array}{ll}\text { SWCT } & \text { Single Well Chemical Tracer } \\ \text { GST } & \text { Gamma Ray Spectrometry Tool } \\ \text { PLT } & \text { Production Logging Tool } \\ \mathrm{S}_{\text {or }} & \text { residual oil saturation } \\ \mathrm{S}_{\text {orw }} & \text { residual oil saturation after water flooding } \\ \mathrm{S}_{\text {orc }} & \text { residual oil saturation after surfactant flooding } \\ \mathrm{GWR} & \text { Gas Water Ratio }\left(\mathrm{Sm}^{3} / \mathrm{Sm}^{3}\right) \\ \Phi & \text { porosity } \\ \mathrm{K}_{\mathrm{h}}, \mathrm{K}_{v} & \text { Horizontal and vertical permeability } \\ \mathrm{EtOH} & \text { Ethanol } \\ \mathrm{Etfm} & \text { Ethyl Formate } \\ \mathrm{IPA} & \text { Iso propanol } \\ \mathrm{MeOH} & \text { Methanol }\end{array}$

\section{Acknowledgement}

The authors want to thank Statoil for permission to publish this paper, and the license partners in the Gullfaks Unit graciously allowed publishing this data. Interpretations and conclusions in this paper are those of the authors and do not necessarily reflect the views or position of Statoil or the Gulffaks Unit.

\section{REFERENCES}

1. Gilje E., Kristensen R., Maldal T., Vikane O.: Well Test Verification of the Technical Potential for Improved Oil Recovery by Surfactant Flooding in the Gullfaks Field, Proceedings of the 6th IOR Symposium in Stavanger 21-23 May 1991, VOL 2 Pp $759-768$

2. Garnes J.M., Grung K.E., Skauge A., Aanonsen S.I.: Performance of a Single-Well Surfactant Tracer Test in a North Sea Oil Reservoir, Proceeding of 7 th European IOR Symposium in Moscow, Russia, Oct. 27-29, 1993 (pp 283 - 292)
3. Deans H.A.: Method for Determining Saturation in Reservoirs, U.S. Patent 3,623,842, (Nov. 30: 1971)

4. Wellington S.L. and Richardson E.A.: A Study of the Chemical Assumptions Underlying the EasterBased Single Well Tracer Test, SPE/DOE 24135, presented at SPE/DOE 8th Symposium on EOR in Tulsa 1992

5. Garnes J.M., Mathisen A.M., Scheie A., and Skauge A.: Capillary Number Relations for some North Sea Reservoir Sandstones. SPE/DOE 20264, presented at 7th Symposium on EOR, Tulsa, April 1990 (pp 879-888)

6. Tomich J.F., Dalton, R.L, Deans, H.A., Schallenberger L.K.: Single-Well Tracer Method to measure Residual Oil Saturation. JPT feb 1973 (pp 211218).

7. Deans H.A., Majoros S. and Heemstra R.J.: The Single-Well Chemical Tracer Method for measuring Residual Oil Saturation, Final Report. DOE/ BC/20006-18, october 1980. (pp 8-14 and 55-61) 